\title{
DEL TIGRE DE LA IRA AL TIGRE DEL ENSUEÑO: WILLIAM BLAKE Y JORGE LUIS BORGES
}

\author{
Rafael Cabañas Alamán
}

\begin{abstract}
RESUMEN
Si bien la crítica tiende a atribuir características negativas inherentes al tigre poetizado por William Blake, en el caso de Jorge Luis Borges el péndulo oscila hacia el lado opuesto. Aunque Borges tiene presente en su obra "el tigre de la ira" de Blake, poeta a quien tanto admiraba, el escritor adapta la imagen del tigre con gran originalidad en sus poemas y breves narraciones.
\end{abstract}

\section{ABSTRACT}

Even though critics tend to attribute negative and inherent characteristics to William Blake's tiger, in Jorge Luis Borges case this image goes in the opposite direction. Although Borges bears in mind the "tiger of wrath" of his much admired predecessor, the writer adapts the tiger's image with great originality in his poems and brief narrative stories.

“The Tyger", famoso poema de William Blake (1757-1827) de su colección Songs of Experience, es uno de los poemas que más polémica ha suscitado a la crítica en cuanto a su expresividad, musicalidad, simbolismo y significado global temático ${ }^{1}$ :

Tyger, Tyger, burning bright,

In the forests of the night:

What immortal hand or eye

Could frame thy fearful symmetry?

In what distant deeps or skies

Burnt the fire of thine eyes?

On what wings dare he aspire?

What the hand dare seize the fire?

And what shoulder and what art

Could twist the sinews of thy heart?

And when thy heart began to beat,

What dread hand? and what dread feet? 
What the hammer? what the chain?

In what furnace was your brain?

What the anvil? what dread grasp,

Dare its deadly terror clasp?

When the stars threw down their spears

And water'd heaven with their tears:

Did he smile his work to see?

Did he who made the Lamb make thee?

Tyger, Tyger, burning bright,

In the forests of the night:

What immortal hand or eye,

Dare frame thy fearful symmetry?

(Blake 1970: 42)

Desde los primeros versos, nos planteamos la problemática sobre el origen de la creación del "tigre de la ira", como lo ha llamado Morton Paley (1970: 38). Las sucesivas preguntas retóricas que surgen apuntan, por alusión metonímica, a una clara respuesta: Dios. En el verso ventitrés se reitera la idea enunciada que se cuestionó en el tercero: "the inmortal hand or eye". Los significantes que connotan oscuridad, terror y violencia: "burning", "fearful", "burnt", "fire", "hammer", "furnace", "anvil", "deadly terrors", "stars", "tears", delatan un grito de lamento en el vacío por parte del sujeto poético. La oscuridad de la noche amenaza a aquellos que no podrán librarse de las garras del tigre de ojos de fuego (v. 6), que son víctimas de su ira $^{2}$, y no parece entenderse el motivo por el que el tigre pudo ser creado por Dios como agente del mal.

La voz de descontento, debida a la pasividad de la injusticia divina, la hallamos también en otros poemas de Blake; se palpa de nuevo en "The arguement", en The Marriage of Heaven and Hell: "From these contraries spring what the religious call / good and evil. Good is the passive that obeys reason: / Evil is the active springing from energy" (vs. 10-12. Blake 1989: 105). Y no parece entenderse cómo Aquel que creó el inocente cordero pudo crear lo diabólico, el tigre devorador ${ }^{3}$.

Por otra parte, veamos la posible repercusión que debió tener uno de los sucesos que más conmovieron a Inglaterra algunos meses antes de que Blake compusiera “The Tyger”. Casi todos los periódicos londinenses describieron detallados comentarios, con un claro propósito sensacionalista, sobre el feroz ataque de un tigre a uno de los hijos de Sir Hector Munro cuando iba rumbo a la India:

The Times on Wednesday, 3 July 1793 said: 'A son of Sir Hector Munro has been killed on passage to India. He went ashore with a party at an island where they had put in to water; and reaching with his companions under some trees a tiger sprang from an adjoining thicket, and seizing him in his mouth, tore the unfortunate young man to pieces' (citado por Pedley 1990: 238).

Teniendo como base hechos reales, leemos descripciones horrendas del tigre en publicaciones de la época, como en History of Quadrupes (1790): 
If they are undisturbed they plunge their head into the body of the animal up to the very eyes, as if they were to satiate themselves with blood, which they exaust the corpse of before they tear it to pieces. There is a sort of cruelty in their devastations, unknown to the generous lion (citado en Pedley 1990: 240).

Nos hallamos ante la imagen sanguinaria y real del tigre que, de alguna manera, debió influir a Blake en la creación del tigre malvado ${ }^{4}$. El poeta no era ajeno a dichos sucesos de la época, y más teniendo en cuenta el conocido tono y contenido sensacionalista de la prensa inglesa. El tigre de su poema, más que estar ahí "para que se consuma el error del ser humano con su ira" (Damon 1969: 11), representa el lado destructivo de la naturaleza, el constante acecho de lo diabólico en nuestras vidas.

En cuanto a Borges, la presencia del tigre se presta como estímulo expresivo e imagen dominante en su estética de ficción. El escritor tiene presente a Blake, aunque reconstruye dicha imagen a su manera. En cierta ocasión, Borges comentó en una entrevista:

Encontré una frase en Chesterton, refiriéndose al tigre del poema de William Blake, que es un poema sobre el origen del mal, y dice: 'El tigre es un símbolo de terrible elegancia' y ahí está unida la idea de la belleza con la crueldad que se atribuye a los tigres. Yo creo que, posiblemente, el tigre no sea más cruel que otros animales. De la misma forma, se atribuye astucia al zorro, majestad al león (citado en Escobar 1988: 53).

El tigre representa un atrayente Eros platónico y surge como viva fuente de inspiración en la solitaria búsqueda por la belleza que Borges desea plasmar en su escritura: "There may be a sense in which this classical eros is a desire for beauty, but if so it is a desire to possess that beauty in this sense eros is a generous-spirited love, an attitude towards the beloved, not a mean and grasping desire" (Osborne 1994: 22). El escritor asume la imagen del tigre dentro de un proceso de energía revitalizadora, como guía espiritual en el turbulento camino que va trazando en su poética, lo que nos lleva a otra de las acepciones del mito: "Eros was one of the fundamental causes in the formation of the world, inasmuch as he was the uniting power of love, which brought order and harmony of among the conflicting elements of which Chaos consisted" (Smith 1849: 50).

Volviendo a Borges, en "Nueva refutación del tiempo" (Otras inquisiciones, 1952), se representa la imagen del río que va hacia la muerte, pero percibimos también la representación vital del tigre como recurso de salvación y lucha contra el devenir del tiempo. Se alza el deseo por evitar el final que habrá de llegar, y Borges se introduce dentro de la piel del mito que le obsesiona: "El tiempo es la sustancia de que estoy hecho. El tiempo es un río que me arrebata, pero yo soy tigre; es un fuego que me consume, pero yo soy fuego. El mundo, desgraciadamente, es real; yo, desgraciadamente, soy Borges” (Borges 1974: 771). Si bien el tigre es ahora de fuego, estamos ante un fuego de vida que representa una revelación ante la muerte ${ }^{5}$. Borges no desea transmutarse en el tigre del mal. Como Jesucristo, quien postula en "Juan I, 14" (Elogio de la sombra, 1969): "Mañana seré un tigre entre los tigres / y predicaré Mi ley a su selva, / o un gran árbol en Asia" (vs. 44-46. Borges 1974: 978), Borges proyecta la representación del tigre del bien.

Observamos, por tanto, la desemejanza con el tigre destructivo y con ojos de fuego, descrito en el poema de Blake. Aunque Borges le dará la razón al poeta inglés en su afirmación "Time is a gift of eternity" -como admitió en una de sus entrevistas (Alifano 1984: 64)-, le otorga al tigre un carisma de elegancia, energía y belleza que supedita y reemplaza al tigre de la ira. El escritor enfatiza la conexión positiva entre el tigre y el niño, en cuya relación brilla por su ausencia la idea del mal: 


\begin{abstract}
El tigre de trapo y el tigre de las figuras de la enciclopedia lo han preparado [al niño] para ver sin horror al tigre de carne y hueso. Platón nos diría que el niño ya ha visto al tigre, en el mundo anterior de los arquetipos, y que ahora al verlo lo reconoce, Schopenhauer diría que el niño mira sin horror a los tigres porque no ignora que él es de los tigres o, mejor dicho, que los tigres y él son de una misma creencia, la Voluntad (Borges y Guerrero 1966: 7-8).
\end{abstract}

La madre de Borges comentó en cierta ocasión respecto de la obsesión de su hijo con los tigres:

\begin{abstract}
When he was very young, he would draw animals. Lying down on his stomach on the floor, he would always begin at the end, drawing the feet first. He would draw tigers, which were his favourite animals. Later, from tigers and other savage beasts, he moved to prehistoric animals, about which for two years he read all he could get hold of. Then he became enthusiastic about Egyptian things, and then he read about them -read with no end in sight- until he threw himself into Chinese Literature; he has a lot of books on the subject. In short, he loves everything that is mysterious (citado por Rodríguez-Monegal 1978: 38).
\end{abstract}

Al interés del gran observador por lo oriental y lo exótico, que lo envolvían en un mundo interior de ensoñación, hemos de añadir el contacto personal mantenido entre Borges y los tigres. Sus visitas al zoológico eran frecuentes. Leemos en "Dreamtigers" (El hacedor, 1960):

En la infancia yo ejercí con fervor la adoración del tigre: no del tigre overo de los camaleones de Paraná y de la confusión amazónica, sino el tigre rayado real (...) Yo solía demorarme sin fin ante una de las jaulas en el zoológico; yo apreciaba las vastas enciclopedias y los libros de historia natural por el esplendor de los tigres (Borges 1974: 783).

En otra entrevista, reconoció que el tigre era una de sus mayores obsesiones, junto al espejo y el laberinto. Aunque recuerda temores que lo atormentaban en sus recurrentes pesadillas, no especifica que fueran motivados por el carácter malvado de la fiera, al contrario que sucedía con el espejo, cuya presencia le producía un verdadero "suplicio" (Escobar 1988: 20-1).

Sin embargo, en ocasiones, el tigre es creado en los sueños, como acto voluntario placentero. Leemos de nuevo en "Dreamtigers": "En ese sueño, una pura diversión de mi voluntad, y ya que tengo un ilimitado poder, voy a causar un tigre" (Borges 1974: 783). Ello ocurre para el protagonista de "Las ruinas circulares"; si bien engendra a su hijo soñándolo, siendo ambos inmunes al fuego, Borges parece necesitar del tigre para garantizar su propia existencia. Lo sueña partiendo de las memorias de su infancia. Cuando no consigue el resultado final deseado se enfurece en su infructuoso esfuerzo: “ $\mathrm{O} O$ h, incompetencia! Nunca mis sueños saben engendrar la apetecida fiera. Es como un deseo momentáneamente carnal” (Borges 1974: 783) ${ }^{6}$.

En "El otro tigre" (El hacedor, 1960) estamos ante el "tigre de símbolos y sombras" que se pasea en "la vasta biblioteca laboriosa", pero no deja de ser "el verdadero tigre de caliente sangre" (Borges 1974: 824). Es la imagen de la que Borges se niega a hacer caso omiso. Imaginamos a una fiera que se va desplazando por los estantes y que representa el sentencioso dinamismo que brota del pensamiento del escritor. Juntos emprenden la aventura del aprendizaje. Pero el narrador busca "un tercer tigre" en "su aventura indefinida", "el que no está en el verso" (Borges 1974: 825). Dicha imagen representa una metáfora de pasión que transciende al deseo carnal y que está prácticamente ausente en la escritura ${ }^{7}$. El sujeto poético precisa del amor del tigre para reafirmar su propia existencia y para sentirse completo. Lo concibe en un contexto platónico asociado al amor ${ }^{8}$. 
Por otra parte, en "El oro de los tigres" (El oro de los tigres, 1972) se rememora el tigre de Bengala de la niñez, pero captamos la preocupación por la falta de libertad "Detrás de los barrotes de hierro / Sin sospechar que eran su cárcel” (vs. 5-6. Borges 1974: 1139). Aunque estamos ante un tigre bello y majestuoso, los ojos que miran atrás advierten las limitaciones del enjaulado animal, posiblemente y una vez más como reflejo del yo poético. Se observa la carencia de libertad de la fiera, detalle que Borges debió notar en su niñez. Tal vez le hubiera gustado liberarlo, reencarnándolo en "El tigre de fuego de Blake" (Borges 1139). Pero ni siquiera a este tigre enjaulado le infundirá Borges la idea del mal, sino que pasará a concederle la posibilidad de procreación, en un marco fantástico, para garantizar su supervivencia: "El metal amoroso que era Zeus, / El anillo que cada nueve noches / Engendra nueve anillos y éstos, nueve, / Y no hay un fin" (vs. 10-13. Borges 1974: 1139)9.

Tal elección de los anillos no resulta arbitraria en "El oro de los tigres". Representa continuidad, evolución y totalidad (Planells 1989, 1990: 6). De ahí que aflore el concepto de reproducción incontrolada. Los anillos simbolizan la perfección y representan un emblema adicional de preciosismo estético que conduce la mirada hacia el futuro dentro de una patente intemporalidad.

Por último, finaliza el poema con un lirismo singular y con la utilización de vocablos sencillos y convencionales que contrastan con el contenido de los versos anteriores, produciéndose efectos dispares. El amor nuevamente se hace notar en el corazón del poeta con la expresión de una clásica metáfora convencional: "Oh ponientes, oh tigres, oh fulgores / Del mito y de la épica, / Oh un oro más precioso, tu cabello / Que ansían estas manos” (vs. 19-22. Borges 1974: 1139) ${ }^{10}$.

Incluso cuando Borges sitúa al tigre en su medio natural, en la selva, emerge un hombre más malvado que la fiera, como sucede en su prosa "Simón Carvajal" (1975), en la que el tigrero no nos causa compasión ninguna. Poco nos importa que pueda ser devorado, pues sentimos lástima por la "amarilla fiera", cuyo "blanco vientre quedaba expuesto. El animal sentía que el acero le entraba hasta la muerte” (Borges 1989: 93).

Otro poema, "El tigre" (Historia de la noche, 1977), empieza y acaba con las dos palabras que más definen al tigre del escritor: energía y amor. De nuevo, como en "El oro de los tigres", se rememora el aprisionamiento de la fiera:

Iba y venía, delicado y fatal, cargado de infinita energía, del otro lado de los firmes barrotes y todos lo mirábamos. Era el tigre de esa mañana, en Palermo, y el tigre del Oriente y el tigre de Blake y de Hugo y Shere Khan, y los tigres que fueron y que serán y asimismo el tigre arquetipo (Borges 1977: 35).

El tigre de Blake queda de nuevo mencionado, pero es suspendido como un eco sin repercusión que Borges no evita y respeta. No le niega un espacio en sus líneas pero sí la posibilidad de incorporarse al concepto que tiene de su propio tigre como aliado.

La recurrencia del tigre se encuentra también en el breve relato "Tigres azules" (Veinticinco de agosto, 1983), en el que el profesor escocés, protagonista narrador, cuenta: “(de niño) cuando me fueron revelados los 'Jungle Books' me desagradó que Shere Khan, el tigre, fuera el enemigo del héroe. A lo largo del tiempo ese curioso amor no me abandonó". Y confiesa: "acaso el amor de los tigres fue el que me trajo de Aberdeen al Punjab" (Borges 1989: 381).

No podemos dejar de identificar esta voz con la del sujeto poético en "El otro tigre", quien perseveraba: "en buscar por el tiempo de la tarde / El otro tigre, el que no está en el 
verso" (vs. 48-49. Borges 1974: 825). La conexión "fiera" y "sueños" queda también reiterada en "Tigres azules": "El curso de mi vida ha sido común, en los sueños siempre vi tigres" (Borges 1989: 381). Intuimos que el tigre azul, soñado por el narrador, que también está obsesionado con el felino, es tal vez ese tercer tigre que el escritor seguía buscando en "el otro tigre".

En "Tigres azules", el cazador ansía encontrar la exótica especie: "en un sueño vi tigres de un azul que no había visto nunca y para el cual no hallé palabra justa" (Borges 1989: 381). Tal vez el autor también soñó con el tigre azul, y de repente le sedujo, abandonando momentáneamente el amarillo, de más fácil visualización ${ }^{11}$. El profesor también pasa a revivir un sueño: "A fines de 1904, leí que en la región del delta del Ganges habían descubierto una variedad azul de la especie. (...) Mi viejo amor se reanimó” (Borges 1989: 381). Este "viejo amor", el tigre azul, tigre de la belleza, es uno de los últimos tigres de ensoñación que surgen en la ficción de Borges ${ }^{12}$. Por medio del profesor de lógica, el escritor desea materializar su sueño en la escritura, encontrar al bello tigre azul para dotarle a la fiera de un exotismo fantástico.

En “Tigres azules", el sueño por hallar al tigre no llega a materializarse. Al mirar por una grieta, se observa que el azul colorea en unas piedras, pero no se percibe ningún tipo de satisfacción: "Era, increíblemente, el azul del tigre de mi sueño. Ojalá no lo hubiera visto nunca. Me fijé bien. La grieta estaba llena de piedrecitas, todas iguales, circulares" (Borges 1989: 384). La duplicidad del referente "lo" en "ojalá no lo hubiera visto nunca" es un detalle significativo. Se refiere al azul de las piedras, pero desplazamos la atención al azul del tigre, y por alusión metonímica, la idea corrobora que ese "lo" se refiere al tigre en sí. El profesor tiene miedo pero ¿tal vez a las piedras azules, o al tigre que busca? Examinemos ambas posibilidades.

El temor a las piedras queda confirmado por lo que precede al espanto del hallazgo, donde observamos que se reproducen infinitamente, como los anillos de "El oro de los tigres". La idea de la obsesión por la reproducción en los objetos surge de nuevo en "Tigres azules", donde leemos: "¡Son las piedras que engendran! Mis sueños confundían y multiplicaban esas cosas dispares” (1989: 384). La sustitución del tigre por la de las piedras posee el azul como rasgo sinecdótico y nexo común entre ambas realidades.

De esta manera, el paralelismo entre la percepción del tigre y el concepto de procreación que vislumbramos en "El oro de los tigres" y "Tigres azules" resulta obvio. En ambas ficciones, los anillos y las piedras procrean, pero si bien en el primer caso se acaba con la idea de la mujer idealizada ("Oh un oro más precioso, tu cabello / que ansían estas manos"), aquí no estamos ante el mismo caso. Al terror que producen las piedras se une el causado por la reproducción desmesurada de los discos, cuya multiplicación y división desafían las reglas aritméticas. Tememos una posible devastación causada por la incontrolada reproducción de la materia. Todo pasaría a convertirse en azul, en un espacio inexistente y sin vida.

En cuanto a la afirmación "ojalá no lo hubiera visto nunca”, nos remite al tigre en la estructura gramatical profunda. "Tigre" no puede ser el referente, sino el "azul de las piedras". Sabemos que, al igual que Borges, el narrador va buscando "el otro tigre", azul en este caso. El azul del tigre ha sido hallado en el fondo de la grieta, pero de alguna manera ha habido un sentimiento de decepción. Es por tanto en "Tigres azules" donde el deseo por que se materialice la fiera erótica queda fatalmente defraudado y el sueño es lo único importante: "Ya en mi choza, me quité la chaqueta. Me tendí en la cama y volví a soñar con el tigre. 
En el sueño observé el color; era el del tigre ya soñado y el de las piedrecitas de la meseta" (Borges 1989: 384). Pero ni siquiera en "Tigres azules" aparece el tigre malvado de Blake. Se sugiere una posible destrucción de la materia inerte, lo que por otro lado redime de culpa al tigre azul, que no llega a aparecer en la breve historia.

El tigre de Borges es mucho más que la plasmación de una sencilla imagen que aparece en varios de sus poemas y prosa refinada. Teniendo en cuenta que el escritor recurre a diferentes temas y motivos que demuestran una actitud obsesiva como la muerte, el espejo y el laberinto, el tigre aparece como resultado de un premeditado acto reflexivo e intelectual. El motivo del tigre es fruto y producto de una refundición de fuentes conocidas que revelan el anhelo de perfeccionar y fundir un bello y exótico símbolo de ensueño.

La imaginación de Borges no tiene límites. Retomemos palabras de su madre publicadas en la revista francesa L'Herme: "He threw himself into Chinese literature" (citado por Rodríguez-Monegal 1978: 38). Por ello, es importante entender el significado del tigre tal como se entiende en la China, ya que ejemplifica aspectos positivos que apuntan al descrito por Borges:

\footnotetext{
By the Chinese (...) the tiger, the King of the wild beasts (...) is taken as the emblem of magisterial dignity and sterness, as the model for the courage. Its head was formerly painted on the shields of soldiers, at the wooden covers of the port-holes of forts to terrify the enemy (...). Just as the dragon is chief of all aquatic creatures, so is the tiger lord of all animals (...) symbolises military progress. It is an object of special terror to demons, and is therefore painted on walls to scare malignant spirits away from the neighbourhood of houses and temples. The shoes of small children are often embroidered with tigers heads for the same reason. The god of wealth is sometimes represented as a tiger. In former times Chinese soldiers were occasionally dressed imitating tiger-skins, with tails and all complete (Williams 1969: 394).
}

El poder y la magnificencia del tigre no podrían estar más implícitos en la definición citada. Borges, como los soldados chinos, desea introducirse en la piel de su deseado tigre para que la metamorfosis entre ambos confidentes sea perfecta. Necesita de su protección, fuerza, belleza y estímulo.

El tigre que seduce a Borges no es el bárbaro sino el luchador, el épico ${ }^{13}$, el símbolo de la elegancia. Discrepamos de la opinión de Rodríguez-Monegal, para quien se trata de "(as the poem of Blake) a symbol of nature savage life and also a symbol of pure evil" (1986: 146). Pero ¿dónde está lo malvado en el tigre de Borges? Y pasa a añadir el crítico: "It is the same devotion, and nostalgia, toward all the action, blood and violence which have been lacking in his life" (Rodríguez-Monegal 1986: 147). Que a Borges le atrajera lo épico es bien sabido por todos, pero que este tipo de literatura le emocionara más que cualquier otro género literario nos hace dudar seriamente si el tigre deseado por él era el de la "destrucción".

El tigre que Borges evoca en su obra es el del zoo, el de las leyendas orientales ${ }^{14}$, el tigre amarillo de Bengala15, el "tigre del amor" platónico soñado por su hermana, el de los sentimientos de Cansinos Assens, el tigre de la épica, luchador y protector, pero también es "una serie de tropos literarios / Y de memorias de la enciclopedia" (Borges 1974: 824). Por lo tanto, no estamos ante "el tigre fatal" (Borges 1974: 824), ni ante el tigre de la ira perfilado por William Blake en "The Tyger", sino ante un proceso de adaptación del icono poético inmortalizado por el poeta inglés, tan admirado por Borges, con el que exitosamente se forja un símbolo literario emblemático y proteico, perfilado con suma belleza, originalidad y elegancia por el escritor argentino en su propia ficción. 


\section{Notas}

1. Uno de los renombrados expertos de William Blake, Colin Pedley, escribe: "Likely to have been completed by 10 October 1793" (1990: 238).

2. $\quad \mathrm{Al}$ igual que se percibe en "Book the First", de The French Revolution. A Poem in Seven Books, donde con la dramatización de dicho suceso histórico se denuncia la realización de otro acto punitivo por parte de "the inmortal eye". Las tropas imparten su castigo sin mostrar una clara explicación: "Return; be withdrawn, cloudy war, troops of warriors depart, nor around our peaceable city". V. 239 (Blake, 1989: 139).

3. "The tiger is the incarnation of the divine wrath" (Paley 1970: 59). A pesar de que las citas del Antiguo Testamento que nos ofrece dicho crítico muestran los reproches de los profetas que anuncian un Dios castigador (Isaías 66: 15, Maquías 3: 2, entre otros) no nos convence de que el tigre sea el desdoblamiento del Dios enfurecido en "The Tyger". Hay una clara separación entre Dios y el tigre que impide unificarlos "What immortal hand or eye / Dare frame thy fearful symetry" (vs. 23-24. Blake 1989: 42). Lo mismo sucede al leer: "What the anvil? what dread grasp / Dare its deadly terrors clasp?" (vs. 15-16. Blake 1989: 42). La ira de Dios en la Biblia queda justificada en claros contextos. En el poema no se percibe un tigre cuyos "deadly terrors" se puedan justificar. La posible contraparte positiva de la fiera está ausente en el poema. El tigre que preocupa y obsesiona a Blake es temible, como sucede con el mal, el demonio y la revolución francesa, conceptos que son percibidos como rayos caídos del cielo.

4. Para más información sobre el tema, véase Pedley 1990.

5. En Twenty four hours with Borges, entrevistas llevadas a cabo entre 1981-1983, opina Jorge Luis Borges sobre las famosas palabras de Heráclito: “ 'Time' I would assert that we always feel that strange perplexity which Heraclitus poignantly expressed in his dictum: 'One cannot step twice into the same river.' First of all because de waters of a river flow, are never still. And secondly because we ourselves are a river, a river that continuously flows, we also are ever-changing". Y pasa a añadir: "Time is our main and only problem" (Alifano 1984: 63, 64).

6. Para Freud (1958: 158), soñar con animales salvajes es hallarse en un estado sensual donde surgen instintos malvados. Aplicar esta definición a Borges nos parece ciertamente arriesgada, por el amplio abanico de posibilidades que sugiere el tigre en su obra. Por su parte, Manuel Ferrer considera que el tigre para Borges funciona como un "tótem (...) como impulso sexual" (1984: 289), lo que también nos resulta injustificado tras leer su artículo.

7. Como en "Las ruinas circulares", donde "procreation can be achieved without coition" (Lima 1973: 411).

8. "For Plato love is primary a desire for something that you lack and need and hope to gain" (Osborne 1994: 54).

9. Por medio de la magia poderosa de la escritura Borges, se soluciona el problema de la extinción de los seres cediéndoles la capacidad de reproducirse de manera fantástica, lo cual nos recuerda al sujeto que procrea y sueña a su hijo en Las ruinas circulares.

10. En cierta ocasión, comentó Borges: "Recuerdo haber dicho que en el aire existe la idea del poderío y de la belleza. Mi hermana hizo una vez la observación de que 'los tigres están hechos para el amor' y esto, después, me recordó a un verso de Cansinos-Assens donde él le dice a una mujer: 'Yo seré como un tigre de ternura'" (Escobar 1988: 53).

11. El azul y el bermejo son ahora una niebla

$\mathrm{Y}$ dos voces inútiles. El espejo que miro 
Es una cosa gris. En el jardín aspiro,

Amigos, una lóbrega rosa de la tiniebla.

Ahora sólo perduran las formas amarillas

Y sólo puedo ver para pesadillas.

"El ciego" (Borges 1974: 1098).

12. En una entrevista, confesó: "My fate is to think of all things, of all experiences, as having been given me for the purpose of making beauty out of them" (Barnstone 1982: 83).

13. Borges afirmó en otra entrevista: "Sí, lo épico siempre me ha emocionado más que cualquier cosa a lo largo de toda mi vida. Intelectualmente me ha gustado el género lírico” (Vázquez 1977: 88).

14. Sin duda, las lecturas orientales contribuyeron en gran parte a moldear el tigre borgeano: "Borges va a mitologizar todo conocimiento" (Yurkievich 1994: 55).

15. Borges comentó en otra ocasión: "El amarillo es uno de los colores que más impacto produjo en mi vida, y es por eso que desde niño me impresionó el pelaje de oro y las rayas del tigre” (Escobar 1988: 53).

\section{Bibliografía}

Alifano, Roberto. 1984. Twenty Four Conversations with Borges. Including a Selection of Poems. Housatonic, MA: Lancaux Publishers.

Barnstone, Willis (Ed.). 1982. Borges al Eighty, Conversations. Indiana University Press.

Blake, William. 1970. Songs of Innocence and Experience. Ed. Sir Geoffrey Keynes. Oxford y New York: Oxford University; The Trainon Press.

1989. The Complete Poems. Ed. W. H. Stevenson. Essex: Longman Group UK Limited.

Borges, Jorge Luis. 1974. Obras completas. Buenos Aires: Emecé Editores, S. A.

1977. Historia de la noche. Buenos Aires: Emecé Editores, S.A.

1989. Obras completas. V. 3. Buenos Aires: Emecé Editores, S.A.

Borges, J. L. y Margarita Guerrero. 1966. Manual de zoología fantástica. México: Fondo de Cultura Económica.

Damon, Foster S. 1969. "The Tyger". The Tyger. Ed. Winston Weathers. Columbus, Ohio: The University of Tulsa. 8-12.

Escobar Plata, Dante. 1988. Las obsesiones de Borges. Buenos Aires: Editorial Distal.

Ferrer, Manuel. 1984. "El otro tigre, 'Dreamtigers'." Expliquémonos a Borges como poeta. México: Siglo Veintiuno. 
Freud, Sigmund. 1958. "Symbols in Dreams". The Standar Edition of the Complete Psychological Works. Introductory Lectures on Psycho-Analysis (Parts I and II) (1915-16). V. 15. Trad. y ed. James Strachey. London: Hogarth Press: 158.

Lima, Robert. 1973. "Coitus Interruptus: Sexual Transubstantiation in the Works of Jorge Luis Borges." Modern Fiction Studies. 19 (3): 407-17.

Osborne, Catherine. 1994. Eros Unveiled. Plato and the God of Love. Oxford: Oxford University Press.

Paley, Morton D. 1970. Energy and the Imagination: A Study of the Development of Blake's Thought. London: Oxford at the Clarendon Press.

Pedley, Colin. 1990. "Blake's Tiger and the Discourse of Natural History." Blake, an Illustrared Quarterly. 24 (1): 238-46.

Planells, Antonio. 1989-1990. "La presencia del tigre en la obra de Borges." CA: Explicación de Textos Literarios. 18 (1): 1-16.

Rodríguez-Monegal, Emir. 1986. “Symbols in Borges’ Work.” Modern Critical Views. Ed. Harold Bloom. New York: Chelsea House Publishers: 133-148.

1978. Jorge Luis Borges, a Literary Biography. E. P. Dutton.

Smith, William (Ed.). 1849. Dictionary of Greek and Roman Biography and Mythology. V. 2. Boston: CC. Little and J.Brown.

Vázquez, María Esther. 1977. Borges: Imágenes, memorias, diálogos. Caracas: Monte Ávila editores.

Wiliams, C.A.S. (Ed.). 1960. Encyclopedia of Chinese Symbolism and Art Motives. New York: The Julian Press Inc.

Yurkievic, Saúl. 1994. "De lo gnómico a lo mítico (sobre algunas asombrosas mixturas)”. Barcelona: Anthropos. 142-143: 54-8. 